\title{
Comparative Analysis of Manual Fading and Laser Fading Process on Denim Fabric
}

\author{
Solaiman $^{1, *}$, Joykrisna Saha ${ }^{2}$ \\ ${ }^{1}$ Dept. of Textile Engineering, World University of Bangladesh, Dhaka, Bangladesh \\ ${ }^{2}$ Dept. of Textile Engineering, Mawlana Bhashani Science and Technology University, Tangail, Bangladesh
}

Email address:

solaimanbari@gmail (Solaiman), joykrishnakaratia@gmail.com (J. Saha)

\section{To cite this article:}

Solaiman, Joykrisna Saha. Comparative Analysis of Manual Fading and Laser Fading Process on Denim Fabric. Science Discovery. Vol. 3, No. 6, 2015, pp. 44-49. doi: 10.11648/j.sd.20150306.11

\begin{abstract}
Fading is renowned process to develop fabric outer appearance. Difference types of fading process are applied on denim fabric to modify fabric outer surface. Laser fading, Hand sand brushing and Potassium permanganate (P.P) spraying etc are applied on denim for fading. In this research work, the properties of Modern (Laser) and conventional fading process (Hand sand brushing, PP spraying) were analyzed on denim fabric. A particular design was produced by laser fading at $130 \mu$ s. After that same design is produced by hand sand brushing with the emery paper $(220,320 \& 400$ number papers) and PP spraying with the Potassium permanganate spray. Reflective spectrophotometer was used to determine $\mathrm{L}^{*}, \mathrm{a}^{*}, \mathrm{~b}^{*}$ coordinates, the colour change ( $\Delta E$ values), Yellowness Index (according to ASTM D 1925) and colour efficiency value (K/S). Physical, Mechanical and other aesthetic properties are also tested and the finding results are also compared with untreated (Raw denim) samples. After testing the sample it is found that rubbing fastness is remain unchanged for PP spraying in compare with raw denim but slight changed for Hand sand Brushing and PP spraying. Durability of untreated, hand sand treated, laser treated and PP sprayed fabrics were evaluated in terms of pilling and fastness toward washing and Lighting, using the gray and blue scale (ISO 105-A02-1987) according to ISO standard recommendations and compared with untreated one. Tensile and tearing strength have decreased in compare with raw sample. The most significant decrease of tensile and tearing strength is occurred after hand sand brushed fading.
\end{abstract}

Keywords: Denim Fabric, Laser Fading, Potassium Permanganate (PP) Spraying, Hand Sand Brushed, Yellowness Index

\section{Introduction}

Denim is a study cotton warp-face twill textile in which the weft passes under two or more warp threads. This twill weaving produces the familiar diagonal ribbing of the denim that distinguishes it from duck. It is a characteristic of most indigo denim that only the warp threads are dyed, whereas the weft threads remain plain white. As a result of the warp-faced twill weaving, one side of the textile then shows the blue warp threads and the other side shows the white weft threads. This is why blue jeans are white on the inside [1].The indigo dyeing process, in which the core of the warp threads remains white, creates denim's fading characteristics, which are unique compared to every other textile.

In this modern period, there has long been a demand for denim pants that have a worn appearance and tendency to the faded and worn out look denim trousers raised. Therefore a fading process including several washing steps is applied after desizing [2]. It is possible to manufacture faded denim garments applying different physical processes such as sanding, sand spraying, brushing, embroidering; and chemical processes such as pre-washing, rinsing, stone washing, sand washing, snow washing, stone washing with enzymes, bleaching $[3,4]$.

The laser is a source of energy which can be directed on desired objects and 134 TEKST_L ve KONFEKS_YON $2 / 2009$ whose power and intensity can be easily controlled [6].

According to Ondogan et al. [7], by using a laser it is possible to create a worn look on denim, which could be an alternative method to conventional processes. From these results he stated that an infrared laser is a suitable tool for the decolouration of indigo-dye on denim fabric. In comparison with conventional techniques of processing denim fabric, a laser beam provides us with some advantages: it is environmentally friendly with respect to the consumption of chemical agents, has low water consumption, and offers flexibility 
of the process and replications of designs [7 - 10].

\section{Materials}

For this experiment denim Twill fabric was used. The fabric was faded by hand sand brushing, laser fading and PP spraying. The final target of this work is to find the effect of fading by conventional (Hand sand brushed and Potassium permanganate (PP) and modern process (Laser) for a specific design on denim fabrics. Denim fabric was collected from Sinha Textiles. The sample (2/1 Right Hand Twill) weight was $357 \mathrm{gm} / \mathrm{m}$ with a warp density 78 ends/inch $(10 \mathrm{Ne}$ slub yarn) and weft density is 46 picks/inch ( $9 \mathrm{Ne} \mathrm{OE})$. The fabric was produced in the air jet loom. The yarns of the fabrics were dyed by indigo-dyes. For hand sand brush emery paper was used, for laser fading $\mathrm{CO}_{2}$ (10.6 micro-meters) laser was used and PP spraying potassium permanganate was used. Fastness Tester, Beesleys balance, Light fastness Tester, Crocking meter, Stop watch, crease recovery tester, Tensile and Tearing strength tester and Spectrometer were used to do the physical, mechanical and visual properties of the denim fabrics.

\section{Methods of the Experiments}

\subsection{Technique of Laser Fading Process}

In this study, the beams from a $\mathrm{CO}_{2}(10.6 \mu \mathrm{m})$ laser was used for the fading of denim fabrics. The Specifications of the machine is

- Model Marcatex 150/250 flexi

- Average output power $150 / 250$ watts

- Peak output power $230 / 400$ watts

- Working frequency $50 / 60 \mathrm{~Hz}$

- Wavelength of laser beam 10.6 micrometre

- Polarisation linear

- Time mode pulse.

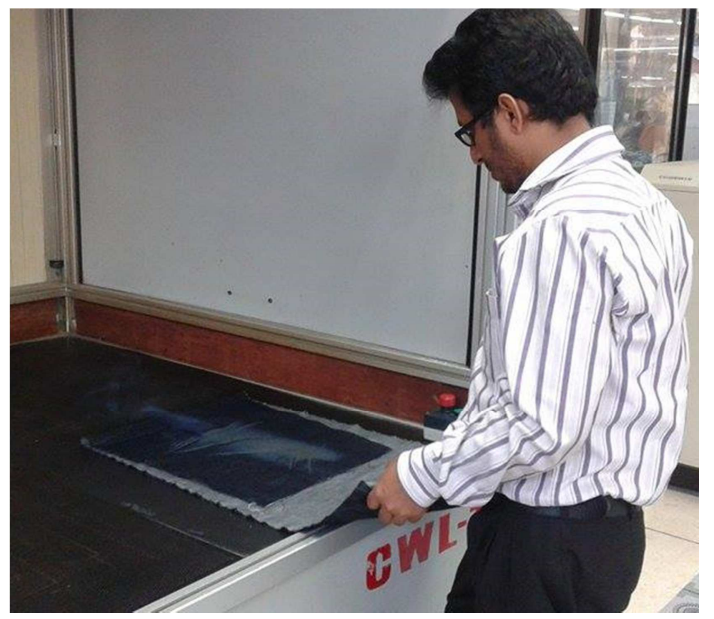

Figure 1. Laser fading Process.

\subsection{Technique of Hand Sand / Scraping}

Emery paper was being used to scrape the garments in par- ticular placement \& design. Emery paper comes in different number generally start from 40 till 600 and above, higher the numbers finer the emery paper, lower the coarseness of the paper. In the experiment from $220,320 \& 400$ number papers were most popular $\&$ widely used.

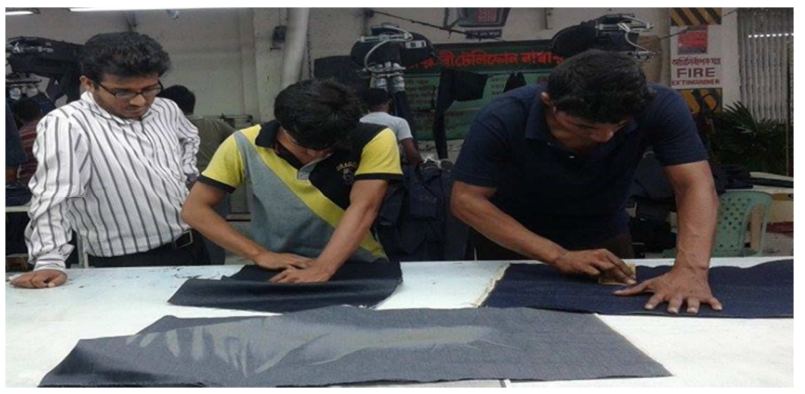

Figure 2. Hand Sand Process.

\subsection{Technique of Potassium Permanganate (PP) Spraying Process}

Potassium permanganate spray in best was done in specific spray booths, where rubber dummies were installed for holding garments. Specific dummies were used for different sizes and styles. This system leads the spray to treatment room where the chemical mixed air was usually passed through the water showers. Potassium permanganate was dissolved in water and the clean air was blown to open. Shower water was further treated with mild quantities of neutralizer before adding to main drain. But where the potassium permanganate spray was used in low concentrations then there was no need to treat shower water.

\subsection{Technique of Colour Measurement Process}

The colour intensities of the untreated, Laser faded, Hand sand brushed and PP sprayed for a specific design and constructed fabrics were measured and compared using a UV VIS-NIR reflective spectrometer(Spectra Flash SF $600 \mathrm{X}$, USA), over the range of 400 to $700 \mathrm{~nm}$.

\section{Testing and Analysis}

\subsection{Determination of Yellowness Index (YI), Colour Yields (K/S and Colour Difference ( $\triangle E$ )}

The spectrophotometer was used for measuring the Yellowness Index(YI), Colour Yields(K/S and $\Delta \mathrm{E}$ of all the treated and untreated samples was the Spectra Flash SF $600 \mathrm{X}$, USA. All the treated samples were measured in a visible region, i.e., a wavelength range from $400-700 \mathrm{~nm}$, with an interval of $10 \mathrm{~nm}$. The mean value was taken for each sample. The colour difference $\Delta \mathrm{E}$, YI values and $\mathrm{K} / \mathrm{S}$ were calculated according to the following equations.

$$
\begin{gathered}
\Delta E=\sqrt{(\Delta L *)^{2}+(\Delta a *)^{2}+(\Delta b *)^{2}} \\
\frac{K}{S}=\frac{(1-R) 2}{2 R}
\end{gathered}
$$


Where, $\mathrm{R}$ is reflectance factor

$$
Y I=\frac{100(1.2769 \mathrm{X}-1.0592 \mathrm{Y})}{\mathrm{Y}}
$$

Where, $\mathrm{X}, \mathrm{Y}$ and $\mathrm{Z}$ are the measured tristimulus values of the specimens.

\subsection{Determination of Color Fastness to Rubbing}

Take the samples of 18 " to 12 " dimension in warp direction. Then take crocking cloth $\left(5 \times 5 \mathrm{~cm}^{2}\right) \&$ put on the crock finger $\&$ clamp it by spring clip. Put the test sample on the crocking bed \& clamp it by cage. Then press the digital counter to set Zero \& start 10 cycles for rubbing, one cycle per second.Colour fastness to rubbing is determined by ISO 105x12; 1993; BS EN ISO 105x12; 1995, AATCC 8).

\subsection{Determination of Light Fastness}

Make a sample at a dimension of $3 \mathrm{~cm}$ in length $\mathrm{x} 20 \mathrm{~cm}$ in width. Place the specimen horizontally on a hard paper along with the blue wool light fastness std. Grade 3.5/3-4 or 4 and pined up. Cover the half portion of the sample attached by a hard paper and pinned up. Open the door of the machine and place the specimen on the testing bed. Close \& lock the door of the machine. Colour fastness to rubbing is determined by ISO 105 B02 \& AATCC 16E.

\subsection{Determination of Abrasion and Pilling Resistance}

Cut the sample according to the template (Abrasion Dia. $3.75 \mathrm{~cm} \&$ Pilling Dia. $13.9 \mathrm{~cm}$ Cutter). For pilling same fabric is used (one test sample $\&$ other the same fabric of test are required) and for abrasion one test sample $\&$ one standard abrading fabric are required. Then for Pilling, test sample is placed face down on pilling specimen holder and other fabric is placed face upward on piling table. Abrasion and Pilling Resistance are determined by ASTM D 4966 \& ISO 12945-2 for Abrasion and ASTM D 4970 \& ISO 12947-2.

\subsection{Determination of Tensile Strength}

Cut the samples according to the template at warp and weft direction $(20 \times 13 \mathrm{~cm}, 20 \mathrm{~cm}$ is always at required direction). Place the sample in between the jaws and close the jaw. Press the start button to start and test that means to break the sample. Tensile Strength is determined by ISO 13934-2 \& ASTM D 5034.

\subsection{Determination of Tearing Strength}

Cut the samples according to the template $(80 \times 58 \mathrm{~cm}, 80$ $\mathrm{cm}$ is always at required direction) from left, middle and right. Place the pendulum at the notch point and put the samples in the jaw and clamp it ( $80 \mathrm{~mm}$ is parallel to horizontal \& $58 \mathrm{~mm}$ is vertical direction). Notch the sample by sharp knife $(15 \mathrm{~mm})$. Release the pendulum by depressing pendulum stop point to sewing a full cycle for tearing the fabric before releasing the stop button. Tearing Strength is determined by ISO 13937-2 \& ASTM D1424).

\section{Results and Discussion}

\subsection{Results of Colour Measurement}

The colour measurement values and changes in Yellowness Index of the untreated, Hand-sand brushed, Laser faded and PP sprayed are given in the table 1 .

Table 1. For colour measurement.

\begin{tabular}{lllllll}
\hline Fading process & $\Delta \mathbf{L}^{*}$ & $\Delta \mathbf{a}^{*}$ & $\Delta \mathbf{b}^{*}$ & $\Delta \mathbf{E}^{*}$ & $\mathbf{Y I}$ & $\begin{array}{l}\mathbf{K} / \mathbf{S} \\
\mathbf{v a l u e}\end{array}$ \\
\hline $\begin{array}{l}\text { Untreated fabric } \\
\text { Hand Sand }\end{array}$ & 0 & 0 & 0 & 0 & -11.68 & 1.32 \\
Brushing & 11.11 & -2.02 & -3.46 & 11.81 & -26.07 & 3.48 \\
Laser Fading & 8.46 & -0.38 & 0.85 & 8.51 & -4.91 & 3.13 \\
PP spraying & 5.56 & -0.78 & -3.76 & 6.76 & -29.84 & 2.20 \\
\hline
\end{tabular}

$\Delta \mathrm{L}^{*}=\mathrm{L}^{*}$ sample $-\mathrm{L}^{*}$ standard, $\Delta \mathrm{a}^{*}=\mathrm{a}^{*}$ sample $-\mathrm{a}^{*}$ standard, $\Delta \mathrm{b}^{*}=\mathrm{b}^{*}$ sample $-b^{*}$ standard

In order to determine the shade of untreated and treated samples, The CIE $\Delta \mathrm{L}^{*} \Delta \mathrm{a}^{*} \Delta \mathrm{b}^{*}$ measurement system is adopted, with the result being shown in table 1 .

In general, $\Delta \mathrm{L}$ indicates how much lighter or darker the treated sample in compare with untreated sample. The higher the $\Delta \mathrm{L}^{*}$ value, the lighter the shade of the sample. The $\mathrm{L}^{*}$ value of The Untreated sample was 22.55 and for Hand sand treated, laser treated and PP treated were 33.66, 31.02, 28.12 respectively. When compared, the hand sanding process could increase the $\Delta \mathrm{L}^{*}$ of the treated sample with at least a $49.26 \%$, Laser faded could increase $37.51 \%$ and PP spray could increase $24.65 \%$. Hence, the Hand sand brushing was considered as an effective colour fading process for denim fabric in meeting the fashion need.

The $\Delta \mathrm{a}^{*}$ value represents the how much reddish or greenish of a sample in compare with standard sample (here Untreated sample).The more negative the value of $\Delta \mathrm{a}^{*}$, the more green the shade of the sample. From the table 1. It is concluded that hand sand brushed fading produced more greenish sample.

The $\Delta \mathrm{b}^{*}$ value represents the how much yellowness or blueness of a sample in compare with standard sample (here Untreated sample). The more negative the value of $\Delta b^{*}$, the more bluish the shade of the sample. From the table 1 . It is accomplished that PP spayed fading produced more bluish sample and Laser sprayed fading made yellowish sample as thermal oxidation effects contributed in this process.

Yellowness Index (YI) is a number calculated from spectrophotometric data that describes the change in colour of a test sample from clear or white toward yellow. This test is most commonly used to evaluate colour changes in a material caused by real or simulated outdoor exposure. The negative values of YI denote departure toward blue. From the table 1 it is seen that PP sprayed sample quit more in blue color and then Hand sand brushed sample.

The colour yield $(\mathrm{K} / \mathrm{S})$ is increased for all treated sample. The K/S value is high for Hand sand brushed sample that mean the breakdown of indigo-dye is higher for this sample. 


\subsection{Determination of Color Fastness to Rubbing}

This test is designed to determine the degree of colour which may be transferred from the surface of a coloured fabric to a specify test cloth for rubbing (which could be dry and Wet).

Table 2. For rubbing fastness.

\begin{tabular}{|c|c|c|c|c|c|c|c|}
\hline \multicolumn{2}{|c|}{$\begin{array}{l}\text { Colour Fastness to Rubbing of } \\
\text { Raw Denim }\end{array}$} & \multicolumn{2}{|c|}{$\begin{array}{l}\text { Colour Fastness to Rubbing After } \\
\text { Hand sand Brushing }\end{array}$} & \multicolumn{2}{|c|}{$\begin{array}{l}\text { Colour Fastness to Rubbing After } \\
\text { Laser Fading }\end{array}$} & \multicolumn{2}{|c|}{$\begin{array}{l}\text { Colour Fastness to Rubbing Afte } \\
\text { PP Spraying }\end{array}$} \\
\hline Dry & Wet & Dry & Wet & Dry & Wet & Dry & Wet \\
\hline 4.0 & 2.5 & 3.5 & 1.0 & 3.5 & 1.5 & 4.0 & 2.0 \\
\hline
\end{tabular}

It is seen in wet condition the hand sand brush rubbing is very poor. The fastness of rubbing in laser fading is significant staining to deep staining.

\subsection{Determination of Washing \& Light Fastness}

One of the most important parameters for high quality fading in terms of serviceability is colour fastness which is also a measure of the stability of the dye. In this thesis work, durability of untreated, hand sand treated, laser treated and PP sprayed fabrics were evaluated in terms of fastness toward washing and Lighting, using the gray and blue scale (ISO 105-A02-1987) according to ISO standard recommendations and compared with untreated one. The results of the relevant tests are presented in the table 3. Laser treated and PP sprayed sample respectively.

The result show that Wash fastness by Hand sand treated and PP sprayed on denim fabrics has been improved but has reduced largely for laser treated sample. The adhesion between dyestuff and surface of fibres can improve cause of morphological changes and creation of functional groups after Hand sand treated and PP sprayed. On the other hand Light fastness is excellent for hand sand treated sample and good (Slight loss in depth) and fair (Appreciable loss in) for both Laser treated and PP sprayed sample respectively.

Table 3. For Washing \& Light fastness.

\begin{tabular}{ll|l|l}
\hline Samples & \multicolumn{2}{l}{ Washing fastness } & Light fastness \\
\hline & $\begin{array}{l}\text { Colour } \\
\text { Change }\end{array}$ & $\begin{array}{l}\text { Staining } \\
\text { Change }\end{array}$ & \\
& 3.5 & 3.0 & 4.0 \\
\hline Untreated & 4.0 & 3.0 & 4.0 \\
Hand sand treated samples & 2.0 & 2.0 & 3.5 \\
Laser Treated sample & 3.5 & 3.0 & 3.0 \\
PP Spraying sample & & & \\
\hline
\end{tabular}

\subsection{Determination of Abrasion Resistance}

Abrasion resistance is the ability of a fabric to resist surface wear caused by flat rubbing contact with another material. There are two different test methods commonly used by the textile industry to assess abrasion resistance: Wyzenbeek and Martindale. This test is contacted by Martidale abrasion tester.

The abrasion resistance of the denim fabrics were measured according to the revolution number until the two yarn breakages realized and values are given above table. Abrasion resistance remains unchanged for both treated and untreated fabric at 1200 number of cycle. No fabric rupture is occurred during abrasion.

\subsection{Determination of Pilling Resistance}

Pilling is a fabric surface characterized by little pills of entangled fiber clinging to the cloth surface and giving the garment unsightly appearance. The pills are formed during wear and washing by the entanglement of loose fibers which protrude from the fabric surface

Pilling resistance property for the treated and untreated sample is remaining almost unchanged.

\subsection{Determination of Tensile Strength}

The tensile strength values of the denim fabrics subjected to different fading process and the decrease in tensile strength values of the treated samples calculated based on the untreated sample tensile strength are represented table 6 .

Due to the fact that, any decrease in tensile strength values indicates damage in fabric structure, different fading process cause a decrease in tensile strength values. However the most significant decrease is occurred after hand sand brushed fading.

The loss in tensile strength values is higher for warp direction compared than weft direction.

\subsection{Determination of Tearing Strength}

In simpler terms Tear resistance (or tear strength) is a measure of how well a material can withstand the effects of tearing. it is usually measured in $\mathrm{kN} / \mathrm{m}$ or pound (lb)

As it can be seen from table 7 , fading process causes a decrease in tear strength values in warp direction and it is significant for Hand sand brushed denim fabric.

Table 4. For abrasion resistance.

\begin{tabular}{|c|c|c|c|c|}
\hline No of Cycle & $\begin{array}{l}\text { Abrasion Resistance on fabric } \\
\text { Before Treatment }\end{array}$ & $\begin{array}{l}\text { Abrasion Resistance after Hand } \\
\text { Brushing }\end{array}$ & $\begin{array}{l}\text { Abrasion Resistance } \\
\text { after Laser Fading }\end{array}$ & $\begin{array}{l}\text { Abrasion Resistance after PP } \\
\text { Spraying }\end{array}$ \\
\hline \multirow{2}{*}{12000} & Colour change 2.0 & Colour change 3.0 & Colour change 3.0 & Colour change 3.0 \\
\hline & No Fabric Rupture & No Fabric Rupture & No Fabric Rupture & No Fabric Rupture \\
\hline
\end{tabular}


Table 5. For Pilling Resistance.

\begin{tabular}{lllll}
\hline No of Cycle & $\begin{array}{l}\text { Pilling Resistance of raw } \\
\text { denim }\end{array}$ & $\begin{array}{l}\text { Pilling Resistance after } \\
\text { Hand sand Brushing }\end{array}$ & $\begin{array}{l}\text { Pilling Resistance after } \\
\text { Laser Fading }\end{array}$ & $\begin{array}{l}\text { Pilling Resistance after PP } \\
\text { Spraying }\end{array}$ \\
\hline 12000 & 4.5 & 4.5 & 4.0 & 4.5 \\
\hline
\end{tabular}

Table 6. For tensile strength

\begin{tabular}{lllll}
\hline & $\begin{array}{l}\text { Tensile strength } \\
\text { Raw Denim (kg) }\end{array}$ & $\begin{array}{l}\text { Tensile strength After Hand sand } \\
\text { Brush Treatment }(\mathbf{k g})\end{array}$ & $\begin{array}{l}\text { Tensile strength After Laser Fading } \\
\text { Treatment (kg) }\end{array}$ & $\begin{array}{l}\text { Tensile strength After PP } \\
\text { Spraying Treatment }\end{array}$ \\
\hline Warp way & 66.03 & 28.6 & 65.16 & 64.33 \\
Weft way & 35.23 & 33.53 & 33.56 & 33 \\
\hline
\end{tabular}

Table 7. For tearing strength.

\begin{tabular}{lllll}
\hline & $\begin{array}{l}\text { Tearing strength Of Raw } \\
\text { Denim (lbs) }\end{array}$ & $\begin{array}{l}\text { Tearing strength After Hand } \\
\text { Sand Brush Treatment (lbs) }\end{array}$ & $\begin{array}{l}\text { Tearing strength After Laser } \\
\text { Fading Treatment (lbs) }\end{array}$ & $\begin{array}{l}\text { Tearing strength After PP Spray- } \\
\text { ing Treatment (lbs) }\end{array}$ \\
\hline Warp & 9.93 & 2.55 & 9.61 & 9.85 \\
Weft & 5.76 & 5.35 & 5.20 & 5.71 \\
\hline
\end{tabular}

\section{Conclusion}

In order to determine the effect of Laser fading process and conventional fading process (hand sand brushing and PP spraying) in terms of colour and mechanical properties, the denim fabrics were faded with $\mathrm{CO}_{2}(10.6 \mu \mathrm{m})$ laser, emery paper and Potassium permanganate spray(PP). According to the results, the Conclusions are as follows:

- The desired colour fading effect can be obtained due to hand sand brushed fading. The yellowness index (YI) changed significantly for hand sand brushed and PP sprayed fading due to removal of carbon particles and sample turned in bluish shade but YI decreased for laser faded sample. The breakdown of indigo-dye is higher for hand sand brushed sample. Due to removal of carbon particles, the yellowness index changed quite significantly after washing.

- It is seen in wet condition the hand sand brushed rubbing is very poor. The fastness of rubbing in laser fading is significant staining to deep staining.

- The result show that Wash fastness by Hand sand treated and PP sprayed on denim fabrics has been improved but has reduced largely for laser treated sample. The adhesion between dyestuff and surface of fibers can improve cause of morphological changes and creation of functional groups after Hand sand treated and PP sprayed. On the other hand Light fastness is excellent for hand sand treated sample and good (Slight loss in depth) and fair (Appreciable loss in) for both Laser treated and PP sprayed sample respectively.

- Abrasion and Pilling resistance remain unchanged for both treated and untreated fabric at 1200 number of cycle.

- From the result it is found that for hands sand brush tensile strength in warp ways is decreased $56.68 \%$, for laser faded tensile strength is decreased $1.31 \%$ and for PP spraying is reduced $2.57 \%$ in compare with raw denim. For hands sand brush tensile strength in weft ways is decreased $4.82 \%$, for laser faded tensile strength is decreased $74 \%$ and for PP spraying tensile strength is reduced $4.45 \%$ in compare with raw denim.

- For hands sand brush tearing strength in weft ways is decreased $4.82 \%$, for laser faded tensile strength is decreased $74 \%$ and for PP spraying tensile strength is reduced $4.45 \%$ in compare with raw denim.

\section{Acknowledgements}

The authors would like to thank Sinha Textile, Mawlana Bhashani Science and Technology University \& World University of Bangladesh for their support.

\section{References}

[1] Denim. (2015, March 25). In Wikipedia, the Free Encyclopedia Retrieved10:21, April7, 2015, from http://en.wikipedia.org/w/index.php?title=Denim\&oldid=6534 25716.

[2] Card A, Moore M. N., Ankeny M., 2006, "Garment washed jeans: impact of launderings on physical properties", International Journal of Clothing Science and Technology, 18(1), 43-52.

[3] Ozguney A., 2007, "The comparison of laser surface designing and pigment printing methods for the product quality", Optics \&Laser Technology, Vol.39, pp.1054-1058.

[4] Sweeney D., 2002, "Way to Go Indigo--Using Cellulase to Soften and Lighten Denim", American Biology Teacher, Vol.64 (3), pp.202-207.

[5] Ondogan Z, Pamuk O., Ondogan E. N., Ozguney A., 2005, "Improving the Appearance of All Textile Products from Clothing to Home Textile Using the Laser Technology", Optics \&Laser Technology, Vol.37(8), pp.631-637.

[6] Ondogan Z., Pamuk O., Ondogan E. N., Ozguney A.; Optics and Laser Technology, Vol. 37 (2005), pp. 631-637.

[7] Spalding I. J.; Which wavelength? How to select a suitable laser, Proceedings of the 4th International Conference on Lasers in Manufacturing, Steed, W. M. (Ed.), pp. 229-234, Birmingham, May 987, IFS Ltd, Bedford, (1987).

[8] Folkes J. A.; Surface Coatings Technology, Vol. 63 (1994), pp. 65-71. 
[9] Dascalu T., Acosta-Ortiz S. E., Ortiz- Morales M., Compean I.; Removal of the indigo color by laser beam-denim interaction, Optics and Lasers Engineering, Vol. 34 (2000), pp. 179-189.

[10] Ortiz/Morales M., Poterasu M., Acosta- Ortiz S. E., Compean I., Henandez- Alvarado M. R.; Optics and Lasers in Engineering, Vol. 39 (2003), pp. 15-24.

[11] Arif Taner ÖZGÜNEY, Gonca ÖZÇELIK, Kadir ÖZKAYA; A Study on Specifying The Effect of Laser Fading Process on The Colour and Mechanical Properties of the Denim Fabrics, Volume: 19 Issue: 2 / APRIL - JUNE 2009.

[12] C W Kan, * C W M Yuen and C W Cheng; Technical study of the effect of $\mathrm{CO} 2$ laser surface engraving on the colour properties ofdenim fabric, doi: 10.1111/j.1478-4408.2010.00270.x.

[13] Shirin Nourbakhsh * and Ali Ashjaran; Laser Treatment of Cotton Fabric for Durable Antibacterial Properties of Silver Nanoparticles, Materials 2012, 5, 1247-1257; doi:10.3390/ma5071247.

[14] Sheila Shahidi, Bahareh Moazzenchi \& Mahmood Ghoranneviss (2013) Improving the dyeability of polypropylene fabrics using laser technology, Journal of The Textile Institute, 104:10, 1113-1117, DOI:10.1080/00405000.2013.774946.

[15] Marie Štěpánková, Jakub Wiener, Josef Dembický; Impact of Laser Thermal Stress on Cotton Fabric, FIBRES \& TEXTILES in Eastern Europe 2010, Vol. 18, No. 3 (80).

[16] ISO 105-X12:2001 Part X12: Colour fastness to rubbing.

[17] AATCC Test Method 8, Colour fastness to Crocking.

[18] ISO 105-B02:2013 Part B02: Colour fastness to artificial light: Xenon arc fading lamp test.

[19] ISO 12945-2:2000, Textiles -- Determination of fabric propensity to surface fuzzing and to pilling.
[20] ASTM D4966 - 98, Standard Test Method for Abrasion Resistance of Textile Fabrics (Martindale Abrasion Tester Method).

[21] ASTM D4966 Standard Test Method for Abrasion Resistance of Textile Fabrics.

[22] ASTM D4970-05, Standard Test Method for Pilling Resistance and Other Related Surface Changes of Textiles Fabrics (Martindale Pressure Tester Method).

[23] ISO 12947-2:1999 Textiles - Determination of the abrasion resistance of fabrics by the Martindale method. Determination of specimen breakdown.

[24] ASTM D5034, Textile Breaking Strength and Elongation Testing.

[25] ISO 13934-2: 2014, Textiles -- Tensile properties of fabrics -Part 2: Determination of maximum force using the grab method.

[26] ISO 13934-2:2014 Textiles -- Tensile properties of fabrics -Part 2: Determination of maximum force using the grab method.

[27] ASTM D1424 - 09(2013)e1 Standard Test Method for Tearing Strength of Fabrics by Falling-Pendulum (Elmendorf-Type) Apparatus.

[28] ISO 13937-2:2000, Textiles -- Tear properties of fabrics -- Part 2: Determination of tear force of trouser-shaped test specimens (Single tear method).

[29] ISO 12945-2:2000, Textiles -- Determination of fabric propensity to surface fuzzing and to pilling -- Part 2: Modified Martindale method of fabrics by the Martindale method Part 2: Determination of specimen breakdown. TC 44. 